\title{
Effectiveness of training parents of beta thalassemia patients in improving medical student-patient communication: a developing country-perspective
}

\author{
*Kavinda Dayasiri ${ }^{1}$, Rasnayaka Mudiyanse ${ }^{2}$ \\ Sri Lanka Journal of Child Health, 2020; 49(4): 369-374
}

\begin{abstract}
Background: Patients and parents with long standing medical problems attending health care facilities over long periods on a regular basis come across medical students repeatedly. A conversation with untrained medical students is perceived as a strain by some patients mainly because they do not understand reasons for some parts of the conversation. Therefore understanding about the process of communication by patients/parents of children has considerable potential benefit to patients themselves. Once the process of the history taking is understood, patient will develop the capacity to provide more meaningful feedback to students.
\end{abstract}

Objectives: To assess parents' satisfaction of medical students' history taking behaviour and medical students' perception of outcomes following training of parents/patients with thalassaemia major in communication skills based on Calgary-Cambridge communication model.

Method: Twenty six final year medical students were assessed quantitatively and qualitatively regarding their history taking experience with twenty six patients having thalassaemia major and their parents at pre-intervention stage. The parents of these children consented for enrolment in a communication skills training programme based on Calgary-Cambridge Communication Model. Each student was permitted to engage with the same patient over the next fortnight subsequent to the intervention. Quantitative evaluation was repeated after a fortnight. Wilcoxon signed rank test was utilised for identifying statistical significance.

\footnotetext{
${ }^{1}$ University Paediatrics, Unit, Peradeniya Teaching Hospital, Sri Lanka, ${ }^{2}$ Department of Paediatrics, University of Peradeniya, Sri Lanka *Correspondence: mbkcdayasiri@gmail.com iD orcid.org/ 0000-0003-0438-9837
}

(Received on 12 December 2019: Accepted after revision on 24 January 2020)

The authors declare that there are no conflicts of interest

Personal funding was used for the project.

Open Access Article published under the Creative

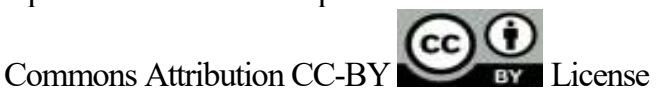

Results: Concerning skills perception (selfreporting) in selected communication components, medical students scored the following before and after intervention: ability to engage with patients $(69 \%, 97.5 \%, \mathrm{p}<0.001)$, talking with patients $(60 \%$, $93 \%, \mathrm{p}<0.001)$, discussing psychological issues $(67 \%, 95.5 \%, \mathrm{p}<0.001)$, discussing socio-economic issues $(63 \%, 95.5 \%, \quad \mathrm{p}<0.001), \quad$ physical examination $(75 \%, \quad 76 \%, \quad \mathrm{p}>0.05), \quad$ giving information $(80.5 \%, 82 \%, \mathrm{p}>0.05)$, giving advice $(73 \%, 73 \%, \mathrm{p}>0.05)$, learning from patients $(83 \%$, $97.5 \%, \mathrm{p}<0.05)$, and obtaining feedback from parents $(70.6 \%, 89 \%, \mathrm{p}<0.05)$.

Conclusions: Training of parents significantly improved medical students' commitment to engaging and talking with thalassaemia patients, and discussing psychological and socioeconomic issues. It was associated with increased commitment to learning and obtaining feedback from parents.

DOI: http://dx.doi.org/10.4038/sljch.v49i4.9269

(Key words: Patient empowerment, medical student, patent communication)

\section{Background}

Thalassaemia presents numerous clinicopsychological challenges in affected children and adolescents spanning a patient's lifetime unless cured by successful bone marrow transplantation. It could cause deformities, retarded growth and delayed puberty ${ }^{1}$. Though there has been a significant increase in the life expectancy of thalassaemia patients, complications are not infrequent $^{2}$. There is a need for better communication skills of the staff caring for a chronic disability such as thalassaemia ${ }^{3}$. Better communication skills also play a key role in arriving at important decisions such as offering bone marrow transplantation to children with beta thalassemia ${ }^{4}$. In this background, the first initiative of the current study was to focus on the perception of thalassaemia patients and their parents about medical students' communication skills.

Studies have shown how patient empowerment models can aid patients with chronic illnesses similar to thalassaemia ${ }^{5}$. Patient empowerment or self-management is thought to be vital to sustain self-care practices and improve long-term 
outcome $^{6}$. There is scanty data on the impact of similar interventions on the health related quality of life (HRQOL) of beta thalassaemia patients. In this background, the present study also assessed the efficacy of a patient-parent communication skills training programme in improving doctor-patient communication.

\section{Objectives}

To assess parents' satisfaction of medical students' history taking behaviour and medical students' perception of outcomes following training of parents/patients with thalassaemia major in communication skills based on Calgary-Cambridge communication model.

\section{Method}

Study was conducted prospectively in the University Paediatric Unit of Teaching Hospital, Peradeniya. Among thirty nine beta thalassemia major patients and their parents initially recruited for the study, twenty six patients and their parents consented for enrolment in the communication skills training programme and participated in the intervention programme. The intervention comprised a communication skills training programme, based on the Calgary-Cambridge Communication Model, and carried out in a single day. A team of staff trained in communication training supported by paediatrician and medical educationist contributed as resource persons to the programme.

Twenty six final year medical students, who had interviewed and examined at least three patients with beta thalassaemia within the preceding 2 weeks, were assessed qualitatively and quantitatively on their experience by the researchers at the pre-intervention stage. Their experience following encounter with recruited 26 young people/ parents were recorded at preintervention level. Each student was permitted to engage with same patient over the next fortnight following the intervention. Quantitative assessment was repeated at the end of the fortnight. Wilcoxon signed rank test was used for identifying statistical significance.

In addition, patient's perception was assessed utilising a pre-tested questionnaire by the investigators of the study. Twenty six studentpatient/parent encounters were independently assessed by the patient/ parent and a senior medical professional (paediatric registrar/ paediatric consultant) by direct observation utilising a prevalidated structured check list. Parent, senior medical professional and medical student rated their experience on a Likert scale ranging from 0 10 ( 0 - least satisfied, 10 - most satisfied $)$ and percentages were calculated based on individual scores retrospectively. The study was approved by the Ethics Review Committee of the Faculty of Medicine, University of Peradeniya

\section{Results}

\section{Parents' evaluation}

Patients'/ parents' $(\mathrm{n}=26)$ perceptions regarding communication with medical students were evaluated quantitatively using a structured checklist. All patient/parent - medical student encounters were independently rated (from 0 to 10 ) by senior medical professionals. Table 1 shows parents' evaluation and satisfaction of medical students' communication skills.

Table 1: Parents' evaluation and satisfaction of medical students' communication skills (n=26)

\begin{tabular}{|l|c|}
\hline \multicolumn{1}{|c|}{ Patient - medical student encounter } & Parents' level of satisfaction (\%) \\
\hline Talking to medical students & 86 \\
\hline Physical examination & 74 \\
\hline Discussing psychological problems & 85 \\
\hline Discussing economy related problems & 79 \\
\hline Receiving advice & 89 \\
\hline Learning from patients & 89 \\
\hline General satisfaction & 87 \\
\hline
\end{tabular}

Independent evaluation by parents and senior medical professionals

Table 2 shows independent simultaneous evaluation of specific components of the process of communication skills by parents and senior medical professionals. Key issues included blood transfusions $(86 \%, 94 \%)$, iron chelation $(93 \%$, $100 \%)$ and carrier screening $(93 \%, 94 \%)$, Five percent of parents and $7 \%$ of senior doctors were not satisfied with overall performance of the medical student. 
Table 2: Independent simultaneous evaluation of specific components of the process of communication skills by parents and senior medical professionals $(n=26)$

\begin{tabular}{|l|c|c|}
\hline Item of communication & Rating by parents (\%) & $\begin{array}{l}\text { Rating by senior medical } \\
\text { professionals (\%) }\end{array}$ \\
\hline Self-introduction & 95 & 93 \\
\hline Friendliness & 88 & 92 \\
\hline Enough time to express concerns & 97 & 92 \\
\hline Clarity of questions & 95 & 95.3 \\
\hline Clear explanations & 97 & 91.8 \\
\hline Addressing key issues & 89 & 97 \\
\hline Addressing patients' ideas and concerns & 85.6 & 87 \\
\hline Addressing family problems & 86 & 96 \\
\hline General satisfaction & 92 & 90.1 \\
\hline
\end{tabular}

\section{Qualitative evaluation of medical students at pre-intervention level}

Five focus group discussions were conducted recruiting five to six medical students in each group $(n=26)$. Many students believed that it was difficult to elicit psycho-social health related information from some patients / their parents. Focusing more on factual information, and failing to build up enough rapport and professional relationship, were seen as barriers for eliciting this information. Further, students perceived that asking sensitive information from patients/their parents in detail will upset them when these questions were asked repeatedly by several students. Therefore, they either avoided or asked for only limited information or asked in detail only if the directive came from either patients or their parents. The students also accepted the fact knowing limited information regarding patients' psycho-social health will limit the chances of directing them to appropriate support services as health care providers.

Most students described themselves as being nice and friendly towards thalassaemia patients and their parents. However, many students started asking disease related information straight after introducing themselves and obtaining verbal consent. Only a few students paid attention to starting the conversation with general questions that related to well-being and comfort which could well have put the patient / parent at ease. Receiving feedbacks on communication experience was rarely practised by medical students. History taking was seen only as a time limited task to elicit disease and its management related information by some medical students. Several students believed that getting only factual information from patients / their parents and thanking them would be enough to complete the history taking task. Some students were less insightful regarding the patients' parents' perspective and the potential negative impact of projecting questions relating to psychosocial health on patients with chronic illnesses.

Quantitative evaluation of medical students at pre-intervention and post-intervention stages

Table 3 shows pre- and post-intervention selfreporting scores as reported by medical students with respective probability $(p)$ values.

Table 3: Pre- and post-intervention self-reporting scores as reported by medical students with p-values

\begin{tabular}{|l|c|c|c|}
\hline \multicolumn{1}{|c|}{ Item of communication } & Pre-intervention (\%) & Post-intervention (\%) & p-value \\
\hline Ability to engage with thalassemia patients & 69.2 & 97.6 & $<0.001$ \\
\hline Talking with patients & 60.0 & 93.2 & $<0.001$ \\
\hline Discussing psychological issues & 67.1 & 95.5 & $<0.001$ \\
\hline Discussing socio-economic issues & 63.1 & 95.5 & $<0.001$ \\
\hline Physical examination & 75.2 & 75.8 & $>0.05$ \\
\hline Giving information & 80.4 & 82.0 & $>0.05$ \\
\hline Getting advice & 73.0 & 73.2 & $>0.05$ \\
\hline Learning from patients & 83.0 & 97.6 & $<0.05$ \\
\hline Getting feedback from patients & 70.6 & 88.8 & $<0.05$ \\
\hline
\end{tabular}

\section{Discussion}

Patient engaging in health care is regarded as the "blockbuster drug of the century"7. It can potentially lead to improved health outcome, better patient care, and lower costs ${ }^{8}$. A patient with a chronic disease is faced with many therapy options and self-care challenges requiring healthcare knowledge, capability of navigating services and health care providers, and a proactive approach to engage with health professionals ${ }^{9}$. A doctor's communication skills include the capability of gathering information to facilitate accurate diagnosis, appropriate counselling, giving treatment options, and establishing caring 
relationships with patients ${ }^{10-12}$. Most previous research has studied the effect of training and empowering health professionals in communication skills for building up better doctor-patient relationships ${ }^{13,14}$. However, communication skills have a tendency to decline with time, and doctors in training often lose their focus on holistic patient care $^{15}$.

Though much attention has been paid to physicians' communication, hardly any attention has been paid to patients' communicative contributions to medical interview ${ }^{16}$. Empowering patients with chronic illnesses who have frequent encounters with health professionals, to be better communicators, can have a significant impact on decision making, self-care and overall satisfaction about health care. Patients who communicate well with their doctor will probably share pertinent information for correct diagnosis, follow advice, and adhere to prescribed therapy ${ }^{17-19}$. The current study evaluated medical students' ability to perform structured medical interviews which were rated subsequently by parents and senior health professionals. Most components in communication skills were given a high rating by both parents and senior paediatric doctors. However; skills of discussing psychological and economic issues, addressing patients' ideas and concerns, and physical examination skills left more room for improvement. The possible reasons for higher satisfaction rates could be due to regular training and assessment of communication skills in the medical curriculum and medical students' awareness that they were being assessed during these encounters. Non-satisfaction of a few should energise us to improve the teaching of communication skills to medical students. Training of patients in communication skills is vital to enhance patient participation ${ }^{16}$. Patients, who ask questions, elicit options, express opinions, and state preferences are known to have better health outcomes than those not doing $\mathrm{so}^{20}$.

In previous studies in patient communication skills training, more attention has been paid to questionasking $^{21,22}$. Scanty attention has been paid in patient communication skills training to provision of information by patients, though this is known to play a central role in doctors' decision-making ${ }^{23}$. In some studies, provision is addressed minimally by encouraging patients to report symptoms clearly and completely ${ }^{24,25}$, but in other studies provision is not included at all in the intervention. In the current study, empowerment of thalassaemia patients / parents and training communication skills was based on the Calgary Cambridge Model. The training of patients / parents significantly improved medical students' commitment in engaging and talking with thalassaemia patients, and discussing psychological and socioeconomic issues. It was also associated with increased commitment with learning and getting feedback from patients.

Available data suggest that patient communication skills training enhances physician-patient communication and promotes health outcomes ${ }^{16}$. Several studies which have looked into long term outcomes of patient communication skills training have reported increasing compliance with recommended therapy and follow-up ${ }^{26,27}$. Since there is only limited literature available on this important aspect of patient management in the current setting, the authors suggest further studies.

\section{Conclusions}

Medical students' perception of ability to engage with thalassaemia patients, talking with patients, discussing psychological and socio-economic issues related to patient care can be significantly improved by training of patients / parents based on Calgary-Cambridge communication model.

\section{References}

1. De Sanctis V, Roos M, Gasser T, Fortini M, Rajola G, Galati MC. et al. Impact of long-term iron chelation therapy on growth and endocrine functions in thalassaemia. Journal of Pediatric Endocrinology and Metabolism 2006; 19(4):471-80.

2. Telfer P, Constantinidou G, Andreou P, Christou S, Modell B, Angastiniotis M. Quality of life in thalassaemia. Annals of the New York Academy of Sciences 2005; 1054:273-82.

https://doi.org/10.1196/annals. 1345.035 PMid: 16339675

3. Vardaki MA, Philalithis AE, Vlachonikolis I. Factors associated with the attitudes and expectations of patients suffering from betathalassaemia: a cross-sectional study. Scandinavian Journal of Caring Sciences 2004; 18(2):177-87. https://doi.org/10.1111/j.14716712.2004.0 0267.x

PMid: 15147481

4. Caocci G, Pisu S, Argiolu F, Giardini C, Locatelli F, Vacca A, et al. Decisionmaking

\section{in} adult thalassaemia patients undergoing unrelated bone marrow transplantation: quality of life, communication and ethical issues. Bone Marrow Transplantation 2006; 37(2):165-9. 
https://doi.org/10.1038/sj.bmt.1705236 PMid: 16299541

5. Wong CK, Wong WC, Wan EY, Wong WH, Chan FW, Lam CL. Increased number of structured diabetes education attendance was not associated with the improvement in patient-reported healthrelated quality of life: results from Patient Empowerment Programme (PEP). Health and Quality of Life Outcomes 2015; 13: 126.

https://doi.org/10.1186/s12955-015-03243

PMid: 26264130 PMCid: PMC4533960

6. Steed L, Cooke D, Newman S. A systematic review of psychosocial outcomes following education, selfmanagement, and psychological interventions in diabetes mellitus. Patient Education and Counselling 2003; 51(1):515.

https://doi.org/10.1016/S07383991(02)00 213-6

7. Kish L. The blockbuster drug of the century: An engaged patient. [Accessed on Jan 7, 2019] Available from: http://www.hl7standards.com/blog/2012/0 8/28/drug-of-the-century/[Ref list]

8. Berwick DM, Nolan TW, Whittington J. The triple aim: care, health, and cost. Health Affairs 2008; 27:759-69. https://doi.org/10.1377/hlthaff.27.3.759 PMid: 18474969

9. Chiauzzi E, DasMahapatra P, Cochin E, Bunce M, Khoury R, Dave P. Factors in patient empowerment: A survey of an Online Patient Research Network. Patient 2016; 9(6):511-23. https://doi.org/10.1007/s40271-016-01712

PMid: 27155887 PMCid: PMC5107186

10. van Zanten M, Boulet JR, McKinley DW, De Champlain A, Jobe AC. Assessing the communication and interpersonal skills of graduates of international medical schools as part of the United States Medical Licensing Exam (USMLE) Step 2 Clinical Skills (CS) Exam. Academic Medicine 2007; 82((10 Suppl)):S65-S68. https://doi.org/10.1097/ACM.0b013e3181 41f40a

PMid: 17895694
11. Brédart A, Bouleuc C, Dolbeault S. Doctor-patient communication and satisfaction with care in oncology. Current Opinion in Oncology 2005; 17((14)):3514. https://doi.org/10.1097/01.cco.000016773 4.26454.30

PMid: 15933466

12. Duffy FD, Gordon GH, Whelan G, ColeKelly K, Frankel R, Buffone N, et al. Assessing competence in communication and interpersonal skills: the Kalamazoo II report. Academic Medicine 2004; 79(6): 495-507.

https://doi.org/10.1097/000018882004060 00-00002

PMid: 15165967

13. Harms C, Young JR, Amsler F, Zettler C, Scheidegger D, Kindler CH. Improving anaesthetists' communication skills. Anaesthesia 2004; 59((2)):166-72. https://doi.org/10.1111/j.13652044.2004.0 3528.x

PMid: 14725519

14. Bensing JM, Sluijs EM. Evaluation of an interview training course for general practitioners. Social Science and Medicine 1985; 20((7)):737-44. https://doi.org/10.1016/02779536(85)9006 4-4

15. Di Matteo MR. The role of the physician in the emerging health care environment. Western Journal of Medicine 1998; 168((5)):328-33.

16. Cegala DJ. Patient communication skills training: a review with implications for cancer patients. Patient Education and Counselling 2003; 50(1):91-4.

https://doi.org/10.1016/S07383991(03)00 087-9

17. Henrdon J, Pollick K. Continuing concerns, new challenges, and next steps in physician-patient communication. Journal of Bone and Joint Surgery American Volume 2002; 84A (2):309-15.

https://doi.org/10.2106/000046232002020 00-00019

PMid: 11861738

18. Hall JA, Roter DL, Rand CS. Communication of affect between patient and physician. Journal of Health and Social Behaviour 1981; 22(1):18-30. 
https://doi.org/10.2307/2136365

19. Tongue JR, Epps HR, Forese LL. Communication skills for patient-centered care: research-based, easily learned techniques for medical interviews that benefit orthopaedic surgeons and their patients. Journal of Bone and Joint Surgery American Volume 2005; 87:6528.

https://doi.org/10.2106/000046232005030 00-00027

20. Kaplan SH, Greenfield S, Gandek B, Rogers WH, Ware JE. Characteristics of physicians with participatory decisionmaking styles. Annals of Internal Medicine 1996; 124:497-504.

https://doi.org/10.7326/0003-4819-124-5199603010-00007

PMid: 8602709

21. Socha McGee D, Cegala DJ. Patient communication skills training for improved communication competence in the primary care medical consultation. Journal of Applied Communication Research 1998; 26:412-30.

https://doi.org/10.1080/009098898093655 17

22. Thompson SC, Nanni C, Schwankovsky L. Patient-oriented interventions to improve communication in a medical office visit. Health Psychology 1990; 9:390-404.

https://doi.org/10.1037/0278-6133.9.4.390 PMid: 2373065

23. Frederikson LG. Exploring informationexchange in consultation: the patients' view of performance and outcomes. Patient Education and Counselling 1995; 25:237-46.

https://doi.org/10.1016/07383991(95)0080 1-6
24. Dow MG, Verdi MB, Sacco WP. Training psychiatric patients to discuss medication issues. Effects on patient communication and knowledge of medications. Behaviour Modification 1991; 15:3-21. https://doi.org/10.1177/014544559101510 01

PMid: 2003848

25. Frederikson LG, Bull PE. Evaluation of a patient education leaflet designed to improve communication in medical consultations. Patient Education and Counselling 1995; 25:51-7. https://doi.org/10.1016/07383991(94)0069 6-J

26. Cegala DJ, Marinelli T, Post DM. The effect of patient communication skills training on treatment compliance in primary care. Archives of Family Medicine 2000; 9:57-64.

https://doi.org/10.1001/archfami.9.1.57

PMid: 10664643

27. Roter DL. Patient participation in the patient-provider interaction: the effects of patient question asking on the quality of interaction, satisfaction and compliance. Health Education Monographs 1977; 5:281-310. https://doi.org/10.1177/109019817700500 402

PMid: 346537 